\title{
Observing solar eclipses in the developing world
}

\author{
Jay M. Pasachoff \\ Williams College - Hopkins Observatory, Williamstown, MA 01267, USA \\ email: jay.m.pasachoff@williams.edu
}

\begin{abstract}
Astronomers have opportunities at least twice a year to use partial, annular, or total eclipses of the Sun, or planetary transits, to interest the public in astronomy through their observations. It is important to provide accurate information about the pleasures and hazards of looking toward the Sun. The International Astronomical Union helps by providing knowledgeable information from experienced eclipse observers.
\end{abstract}

Keywords. eclipses: solar, astronomy education

\section{Introduction}

Solar eclipses are perhaps the most dramatic event possible: when it goes dark as night in the middle of the day, people of all locations and all cultures are awed. Contemporary astronomers are even able to discern the locations of eclipses that took place thousands of years ago since ancient records sometimes record such dramatic events, allowing the Earth's changing rotation rate to be determined.

Though it is completely safe to observe the total phase of a solar eclipse, since the brightness of the solar corona is comparable to that of the full moon and therefore equally safe, the partial phases before and after totality can be hazardous to vision. On a normal day, the eye-blink reflex keeps you from staring at the Sun. In the crescent partial phases of a solar eclipse, though, the total flux of solar radiation may be too low to activate the eye-blink reflex while the surface intensity of the remaining image of the solar photosphere can damage the retina. The problem is acute when any optical aid - telescope or binoculars - is used, since retinal damage can be immediate. But the problem can occur if one stares unaided at the crescent partial phase for too long - many seconds or even minutes. Such cases are rare but they do exist. For information on safe observation of eclipses see Chou (1997, 1998), Espenak (1996), Land (2000), Pasachoff and Covington (1993), and Pasachoff (2006).

\section{Safe observation of solar eclipses}

A public education programme is therefore necessary to explain to people in countries over which an eclipse will be visible just why the eclipse is interesting to look at and how to observe it safely (Golub and Pasachoff, 1997; Pasachoff, 2001). We scientists also usually want to overcome local prejudices and pseudoscientific beliefs. Unfortunately, we have found students locked in basement rooms, sometimes even on the side away from the Sun, in, historically, the United States, Canada, and Australia; people refusing to eat food during an eclipse in India; and pregnant women being kept indoors during the eclipse in many countries. Yet we astronomers do have a tremendous teaching opportunity at the times of eclipses, since newspapers and sometimes public authorities tell people about 
the coming eclipse, and for some days in advance of an eclipse we have the attention of many people (Pasachoff, 1996a, 2001).

Accordingly, the International Astronomical Union's Working Group on Solar Eclipses advises people around the world about eclipses, including their scientific value and how to observe them safely. A Programme Group on Public Education at the Times of Solar Eclipses of the IAU's Commission on Education and Development takes advantage of the public attention to aid local astronomers and educators about eclipse safety (Pasachoff, 2002). I chair both groups. The Working Group has as other members Iraida Kim (Russia), Hiroki Kurokawa (Japan), Jagdev Singh (India), Vojtech Rusin (Slovakia) as general members; Fred Espenak (United States) and Jay Anderson (Canada) for providing predictions and the NASA Technical Publications and Website; and Michael Gill, the moderator of the Solar Eclipse Mailing List (SEML@yahoogroups.com; eclipsechaser@yahoo.com). The previous triennium also had Atila Ozguc (Turkey) as a member, because of the 2006 eclipses passing through Turkey. The 2006-2009 triennium has Jingxiu Wang (China) and C. Fang (China) as members because of the 2008 and 2009 eclipses passing through China. The Programme Group has as other members Julieta Fierro (Mexico) and Ralph Chou (Canada), a professor of optometry who has special expertise in eye safety and in solar-filter testing.

The Working Group on Eclipses' Website is http://www.eclipses.info. The site can be reached through a link on the site of the Commission on Education and Development at http://www . astronomyeducation.org, going to Description of Our Activities (Programme Groups). Eclipses.info also contains links to providers of solar-filter materials.

\section{The importance of disseminating public information on eclipses}

An early example of false information from an official source was in a 1970 memo from the Department of Justice in the United States, which misleadingly states, "The public must be made aware that the so-called protective devices, such as sun glasses, smoked glass, or film negatives do not protect the eye from the invisible infra-red rays which do the damage." Some film negatives, those with silver content, indeed do and did protect the eye. So warnings about not using sunglasses or smoked glass are valid, but proper credit to acceptable protective filters should be provided.

An egregious example of public miseducation took place at the 2002 eclipse in Australia, when the official health authorities in Western Australia, where only a partial eclipse would be visible, advised people not to look at the eclipse at all. They even prevented eye-protection solar filters from being sold, on the pretense that even though they were approved in the EU, they had no specific tested verification from an Australian authority. Such people do not listen to the advice of experts, even when we try to describe the truth to them. A 5-cm-high front-page headline in The Advertiser, saying only "DON'T LOOK," gave an inadequate message, and the subheadline, "Eclipse glasses can hurt your eyes," was misleading.

A major problem with such official misinformation is that local people soon find out that, in fact, the eclipse was not harmful and that people they know viewed it with delight. These people may then lose confidence in other official pronouncements, including health warnings about AIDS, STD's, vaccinations, and other important subjects. The negative consequences of false warnings about eclipse eye hazards can thus be severe and widespread. 


\section{March 2006 eclipse in Nigeria}

One of the triumphs of our IAU activities took place in Nigeria during the 29 March 2006 total solar eclipse. Our colleague from there, Prof. P.N. Okeke of the Centre for Basic Space Science, was in touch with us, and we arranged for sheets of solar filter material to be provided. Since eclipse "glasses," with a quantity of solar-filter material in each of two eyes, are expensive in quantity, even at a cost of 50c or $\$ 1$ per item, we have figured out how the filter material can be used much more efficiently. At the very least, individual "glasses" can be cut in half at the bridge, giving two for the price of one. But much more efficiently, only about 4 millimetres square are needed if they are properly mounted in a square or round hole in a card or cardboard. So out of a one metre square piece of filter material, aluminized Mylar or other, one can get 250 filters across or 250 squared, which equals 62500 filters! With labour provided locally in Nigeria to mount the filter material, they were able to make and distribute 400000 solar filters for eye safety at the partial phases of the eclipse. The Federal Ministry of Information and National Orientation of Nigeria provided an excellent poster, asserting, "Come Wednesday 29th March, 2006 Nigeria will witness an eclipse of the Sun. DO NOT BE AFRAID! Solar eclipse is a natural phenomenon which occurs when the moon comes between the Sun and the Earth. It is historical... It could be a once in a life time experience. But DO NOT WATCH with your NAKED EYES. PROTECT YOUR EYES with special filter glasses recommended by the National Space Research and Development Agency." Would that all countries would provide such information, though the distinction between partial and total phases should have been made. A newspaper article even headlined "Total eclipse of March 29, 2006 will be used to educate Nigerians."

\section{Concluding remarks}

The educational opportunities provided at the times of solar eclipses are not limited to the zones in which totality is eventually visible, though certainly the event is more dramatic when totality appears. Furthermore, in the path of totality, one must educate the public as to when they can observe without eye protection (or projection methods) and when it is safe to look at the Sun directly, namely, when only the corona is visible. At the 1973 total solar eclipse in Loiengalani in the northern frontier district of Kenya, the local priest notified people when it was safe to look by ringing the mission's bell.

The path from which a partial eclipse is visible is much more widespread, often covering many countries in the developing world. And about as many eclipses never pass the partial phase. Given that there are as many annular eclipses as total eclipses, each about every 18 months (Golub and Pasachoff, 1997), the addition of half as many partial eclipses means that at least twice a year there is an occasion to explain how to look at the Sun with safety. In recent years, we have also had the 2004 transit of Venus and the 1999, 2003, and 2006 transits of Mercury. In the years to come, we will not have another transit of Venus until 2012 or a transit of Mercury until 2016 (Pasachoff, 2006). Though totality occurs only about every 400 years on average at any given location on Earth, a partial phase of a solar eclipse or a planetary transit can be seen from any given spot almost yearly (Held, 2005; Pasachoff, 2003, 2006).

In sum, we have opportunities at least twice a year to use partial, annular, or total eclipses of the Sun, or planetary transits, to interest the public in astronomy through their observations. It is important to provide accurate information about the pleasures and hazards of looking toward the Sun, and our International Astronomical Union organizations try to help by providing knowledgeable information from experienced eclipse observers. 


\section{References}

Chou, R. 1997, Eye Safety During Total Eclipses, adapted from NASA Reference Publication 1383, Total Solar Eclipse of 1999 August 11, p. 19.

http://www.williams.edu/Astronomy/IAU_eclipses/eclipse_public_info.html http://sunearth.gsfc.nasa.gov/eclipse/SEhelp/safety2.html linked through http://www.eclipses.info

Chou, R. 1998, Sky and Telescope, February 1998, p. 36

Espenak, F. 1996, Eye Safety During Total Eclipses, adapted from NASA Reference Publication 1383, Total Solar Eclipse of 1998 February 26 p. 17 http://sunearth.gsfc.nasa.gov/eclipse/SEhelp/safety.html linked through http://www.eclipses.info

Golub, L., Pasachoff, J.M. 1997, The Solar Corona, Cambridge University Press, Cambridge, UK.

Held, W. 2005, Eclipses 2005-2017 Floris Books, Edinburgh

Land, D. 2000, OK, Look Directly at a Total Solar Eclipse, http://www.williams.edu/Astronomy/IAU_eclipses/look_eclipse.html linked through http://www.eclipses.info

Pasachoff, J.M., Covington, M.A. 1993, The Cambridge Eclipse Photography Guide, Cambridge University Press, Cambridge UK.

Pasachoff, J.M. 1996a, In: Z. Mouradian and M. Stavinschi (Eds.) Theoretical and Observational Problems Relating to Solar Eclipses, NATO Advanced Research Workshop, Sinaia, Romania; 1997, Kluwer, 249-255.

Pasachoff, J.M. 1998, In: L. Gouguenheim, D. McNally, and J. R. Percy, (Eds.) New Trends in Astronomy Teaching, Cambridge University Press, , Cambridge UK, pp. 202-204.

Pasachoff, J.M. 2001, In: Alan H. Batten, (Ed.) Astronomy for Developing Countries, Astronomical Society of the Pacific, pp. 101-106; additional comments on pp. 139-140, 338-339.

Pasachoff, J.M. 2002, In: K. Bocchialini and S. Koutchmy (Eds.) Observations et Travaux, Vol. 53, p. 56, Institut d'Astrophysique, Paris.

Pasachoff, J.M. 2003, The Complete Idiot's Guide to the Sun, Alpha Books, Indianapolis.

Pasachoff, J.M. 2006, A Field Guide to the Stars and Planets, 4th ed, Houghton Mifflin, Boston.

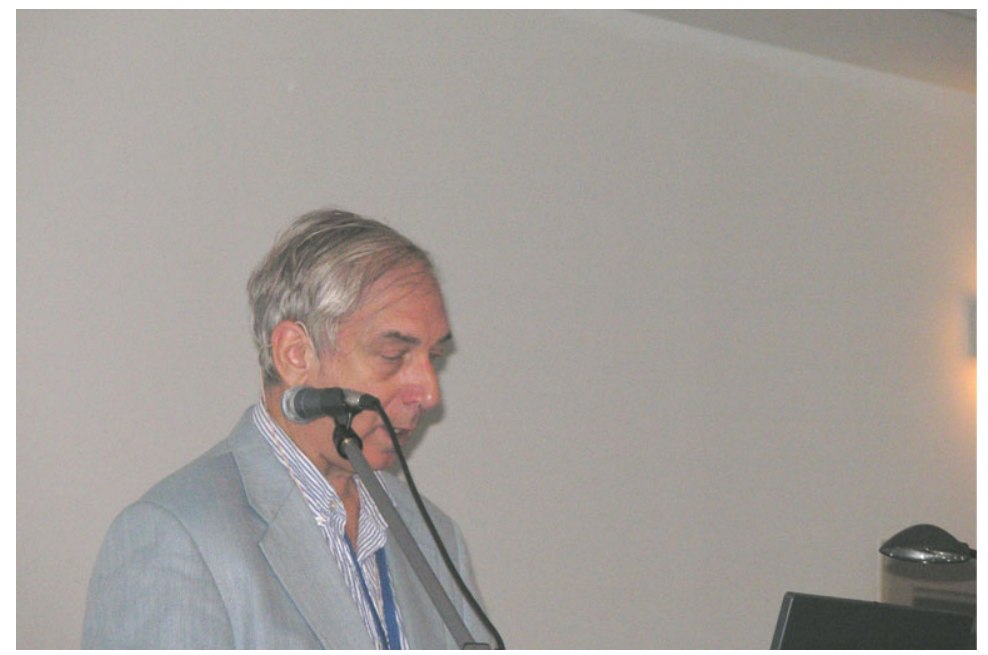

Jay Pasachoff 